Екологічний Вісник Криворіжжя. 2019. Випуск 4. С. 56-66

Ecological Bulletin of Kryvyi Rih District. 2019. Issue 4. P. 56-66

ISSN 2664-505X (print) ISSN 2664-5068 (online)

DOI: 10.31812 /eco-bulletin-krd.v4i0.2560

\title{
МЕДЬ В ПАХОТНОЙ И ЛУГОВОЙ ПОЧВЕ ГОМЕЛЬЩИНЫ
}

\author{
А. Г. Подоляк ${ }^{1}$, А. Ф. Карпенко ${ }^{2}$ \\ 1 - Гомельская областная проектно-изыскательская станиия \\ химизации сельского хозяйства, г. Гомель, Беларусь; \\ 2 - Гомельский государственный университет им. Ф. Скорины, \\ г. Гомель, Беларусь
}

\begin{abstract}
Аннотация. В статье анализируются результаты исследований определения содержания меди в пахотной и луговой почве в районах Гомельской области выполненных с четырёхлетним интервалом. Установлено колебание средневзвешенных показателей меди, в 2013 году, в пахотной почве в пределах 1,44-2,16 мг/кг, в 2017 году - 1,42-2,17 мг/кг почвы, в луговой соответственно $1,55-2,20$ и $1,83-2,20$ мг/кг почвы. Отмечается увеличение количества площадей с более высоким содержанием в почве меди. Если в 2013 году 47,9\% обследованных площадей пахотных почв имели удельную концентрацию меди более 1,51 мг/кг почвы, то по состоянию на 2017 год уже $50,2 \%$, соответственно луговых почв - с $54,2 \%$ до $60,9 \%$.
\end{abstract}

Ключевые слова: почвы, медь, содержание, обеспеченность.

Введение. Медь - элемент побочной подгруппы I группы периодической системы. В земной коре её содержится примерно 0,007 вес.\% или в 600 раз меньше, чем железа. Медь входит в состав более 200 минералов, но главным её источником являются сульфидные руды $[1,3,5,15]$. Почва является особенной частью биосферы, которая не только геохимически аккумулирует компоненты, как природных, так и антропогенных выбросов, но и выступает естественным буфером, контролирующим перенос химических элементов и соединений в атмосферу, гидросферу и живое вещество $[2,4,11,12]$. Микроэлементы, поступающие из различных источников, попадают в конечном итоге на поверхность почвы, и их дальнейшая судьба зависит от ее химических и физических свойств $[13,14,17,18]$.

В настоящее время загрязнение почв происходит главным образом в промышленных районах и в центрах крупных населенных пунктов от предприятий, транспорта, коммунальных сточных вод. Источниками микроэлементов для почв также являются вносимые удобрения, пестициды, полив и орошение $[2,15,19]$. 
Из почвы растения могут накапливать микроэлементы, особенно тяжелые металлы, в тканях вследствие больших возможностей адаптации к изменениям почвенных химических свойств. Поэтому растения являются промежуточным резервуаром, через который микроэлементы переходят из почв в организм человека и животных $[2,15,20]$.

Медь относится к одному из тяжелых металлов в почве. Преобладающей обычно в поверхностных средах подвижной формой меди является катион с валентностью +2 , однако в почвах могут присутствовать и другие ионные формы. Ионы меди способны прочно удерживаться в обменных позициях, как на неорганических, так и на органических веществах $[1,3,18,19]$. Медь является незаменимым элементом в жизни растений и животных. Несмотря на то, что в агрономической практике наибольшее значение имеют растворимые, а, следовательно, подвижные и доступные формы меди в почвах, при геохимических исследованиях основная доля получаемой информации - это валовые содержания меди в почвах $[2,7,15,16]$.

Распределение валовых содержаний меди в поверхностном слое почв различных стран колеблется в пределах 1-160 мг/кг сухой массы почвы $[2,7]$. В песчаных почвах и подзолах Европейской части бывшего СССР в пределах 1,5-29 мг/кг или в среднем 11 мг/кг сухой массы [21], в суглинистой и глинистой почве Томской области в пределах 1-21 мг/кг

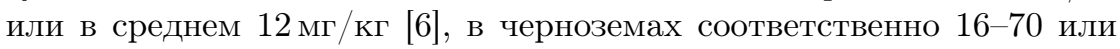
27,5 мг/кг $[6,7,9,12]$.

После поступления в растения медь присутствует в основном в комплексных соединениях с низкомолекулярными органическими веществами и протеинами. Она входит в состав энзимов, имеющих жизненно важные функции для метаболизма растений, играет значительную роль в таких физиологических процессах как фотосинтез, дыхание, перераспределение углеводов, восстановление и фиксация азота, метаболизм протеинов и клеточных стенок. Медь контролирует образование ДНК и PHК, и ее дефицит заметно тормозит репродуцирование растений, оказывает влияние на механизмы, определяющие устойчивость к заболеваниям. На её содержание влияет тип почвы, вид растений, стадия вегетации, внесение медьсодержащих удобрений $[2,7,12]$. В ряде работ сообщалось, что длительное использование неорганических фосфатных удобрений существенно повышает природный уровень меди и фосфора в почвах $[8,9]$.

Внимание практиков связано с такими проблемами медного питания животных как наличие биогеохимических провинций, дефицит меди у молодняка при выпаивании цельного молока и заменителя цельного 
молока, вторичная недостаточность меди из-за её сложных взаимоотношений с другими элементами, опасности хронических медных токсикозов вследствие её неправильного использования в животноводстве или высокого содержания в кормах $[10,11]$.

Цель работы - провести анализ результатов исследований почв на содержание меди в сельскохозяйственных районах Гомельской области.

Материаль и методъ исследований. Материалы работы результаты многолетних исследований почв Гомельской области (Республика Беларусь). Методы исследований - классические методы агрохимии и почвоведения. Кроме того, были использованы общенаучные методы - анализа и синтеза, индукции и дедукции, аналогии и моделирования, абстрагирования и конкретизации.

Резулътатъ и их обсуждения. В рамках Министерства сельского хозяйства и продовольствия в республике исследования агрохимических показателей почв проводят областные проектно-изыскательские станции химизации сельского хозяйства (ОПИСХ). Так, ежегодная работа Гомельской ОПИСХ направлена на обследование сельскохозяйственных земель ряда районов Гомельской области на содержание минеральных веществ в почве, в том числе меди.

Станцией в 2013 году были выполнены исследования сельскохозяйственных земель шести районов Гомельской области и в 2017 году, через четыре года, в этих же районах проведено повторное почвенное обследование. На периодичности обследования и изучения агрохимических показателей строится многолетняя работа предприятия.

В течение этих годов специалистами отдела почвоведения проведено полевое агрохимическое обследование в Октябрьском, Мозырском, Лоевском, Буда-Кошелевском, Кормянском и Чечерском районах. Так, в 2013 году в этих районах было обследовано 174,3 тыс. га, в 2017 году - 187,2 тыс. га пахотных земель сельскохозяйственных угодий в 52 сельхозпредприятиях (табл. 1).

Как следует из показателей таблицы 1 , по содержанию меди в дерново-подзолистой и торфяной почвах применяется четырёх интервальная градация показателей. Анализ результатов исследований свидетельствует, что если удельный вес площадей первого интервала (менее 1,5 мг/кг почвы) в 2013 году составил $52,1 \%$ от всей площади обследованных площадей, то в 2017 году он был ниже на 2,27\%. Если проанализировать показатели четвертого интервала, с самой высокой концентрацией меди, то можно отметить, что удельный вес площадей здесь прирос на $0,98 \%$ с 1,32\% до 2,30\%. Также отмечен прирост площадей на $0,05 \%$ во втором интервале и на $0,65 \%$ в третьем интервале. 


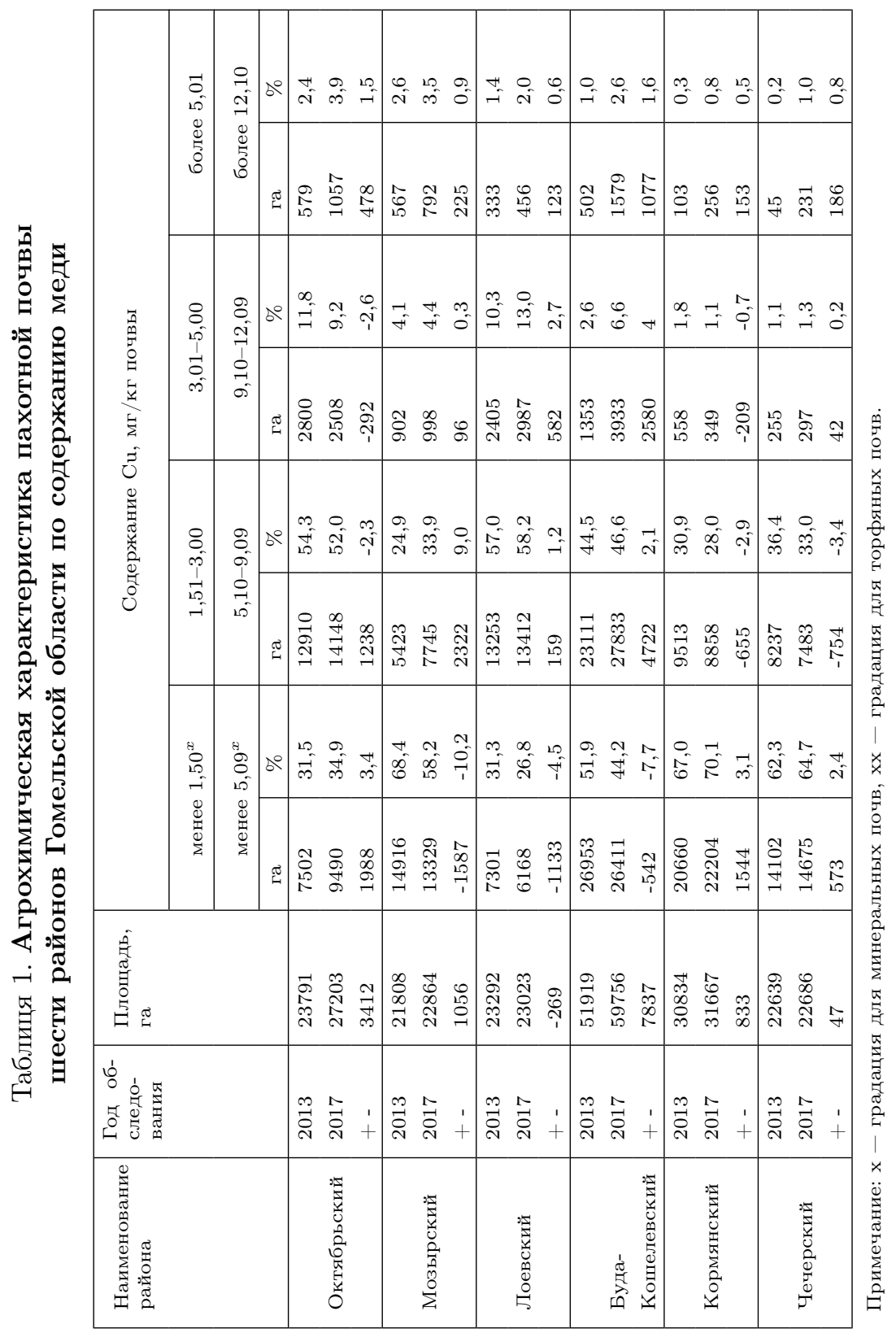


Из этого следует, что наблюдается увеличение количества площадей с более высоким содержанием в почве меди. Если в 2013 году 47,9\% обследованных площадей имели удельную концентрацию меди более 1,51 мг/кг почвы, то по состоянию на 2017 год уже 50,2\%.

При повторном определении средневзвешенное содержание меди в пахотной почве в целом по шести районам на 0,08 мг/кг было выше в сравнении с предыдущим обследованием данных почв (рис. 1). Исключение составляли лишь показатели в Октябрьском и Кормянском районах, где они были соответственно ниже на 0,06 и 0,02 мг/кг почвы. Колебания средневзвешенного показателя по отдельным районам в 2013 году находилось в пределах 1,44-2,16 мг/кг, в 2017 году - 1,422,17 мг/кг почвы.

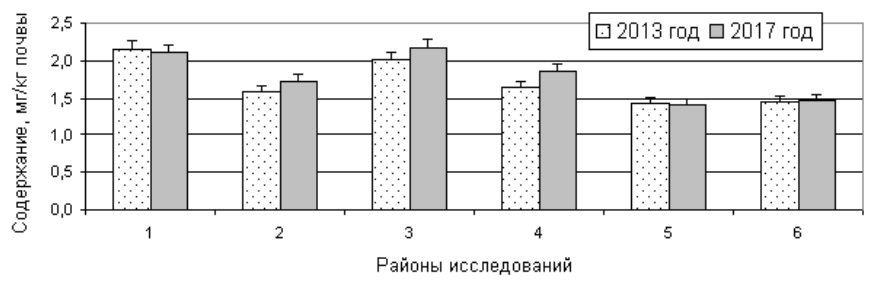

Рис. 1. Средневзвешенное содержание меди в пахотной почве обследованных районов в 2013 и 2017 годах

Районы исследований:

1 - Октябрьский р-н, 2 - Мозырский р-н, 3 - Лоевский р-н,

4 - Буда-Кошелевский р-н, 5 - Кормянский, $6-$ Чечерский

Кроме пахотных почв одновременному обследованию подвергались и луговые почвы (табл. 2). С этой целью были отобраны пробы почвы луговых земель на площади 66,97 тыс. га в 2013 году и 57,0 тыс. га в 2017 году.

Распределение площадей по удельной концентрации в почве меди показало, что если в 2013 году первую группу их попало 45,8\%, во вторую $41,4 \%$, третью группу $9,7 \%$ и четвертую группу $3,1 \%$, то в 2017 году соответственно 39,1, 42,4, 13,1 и 5,4\%. Из этого следует, что количество луговых почв с более высоким содержанием меди увеличилось. Если количество площадей в первой группе уменьшилось на $6,7 \%$, то на такое же количество их приросло во второй-четвертой группах. Во второй группе прирост составил $1,0 \%$, третьей группе $3,4 \%$ и четвёртой группе - $2,3 \%$. Количество площадей луговых земель с содержанием меди более 1,5 мг/кг почвы увеличилось с $54,2 \%$ до $60,9 \%$. 


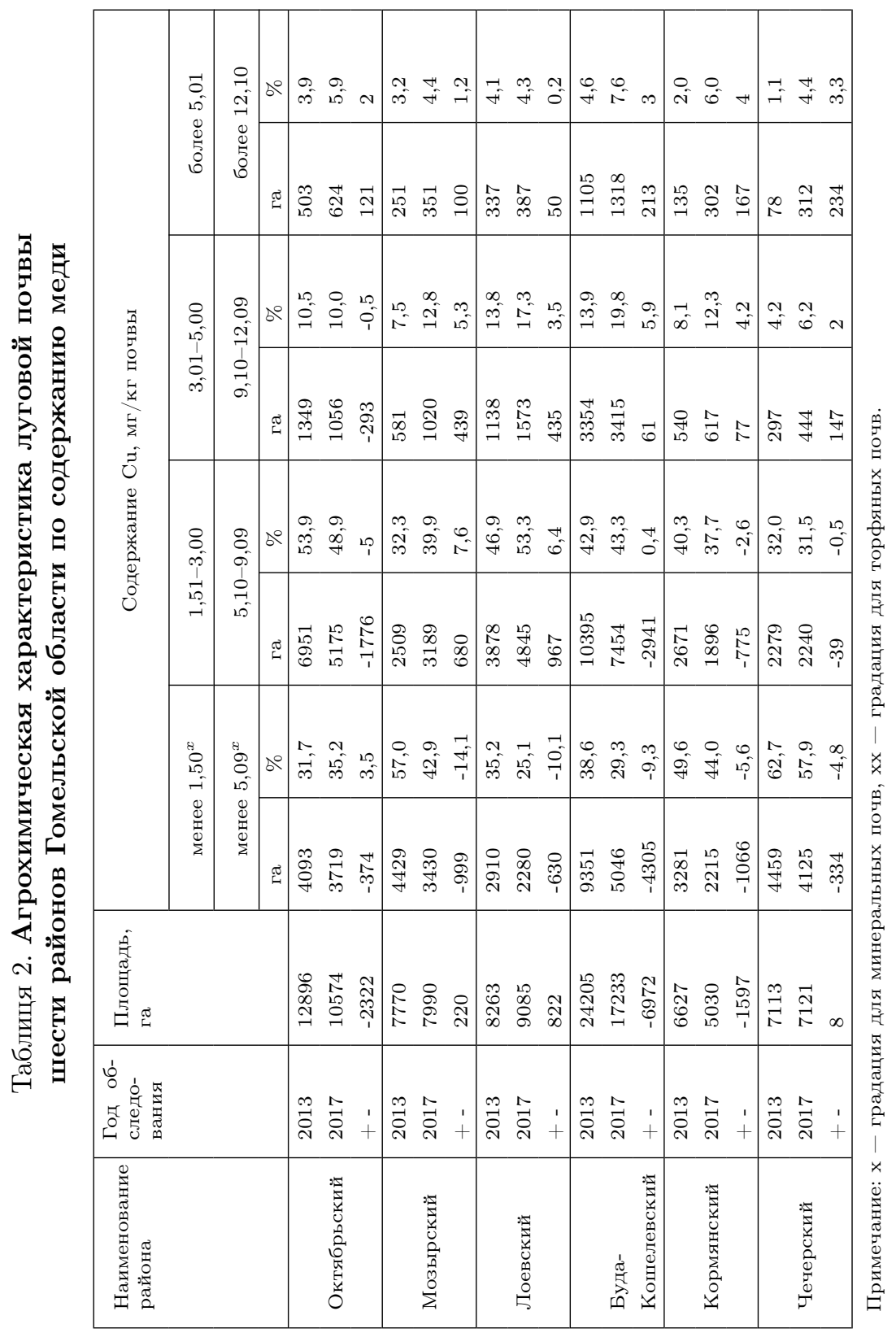


Сравнение пахотных и луговых площадей по содержанию меди свидетельствует, что в первой группе луговых почв в 2017 году находилось $39,1 \%$, пахотных почв - 49,8\%. Из этого вытекает, что содержание меди в луговой почве выше, чем в пахотной. Такая же ситуация наблюдалась и при обследовании почв в 2013 году.

Изменение средневзвешенных показателей содержания меди через четырехлетний период на почвах улучшенных луговых угодий приведено на рисунке 2. Так, только в Октябрьском районе данный показатель в 2017 году был без изменений и на уровне 2,20 мг/кг почвы, в Мозырьском районе выше на 0,25 мг/кг почвы, в Лоевском на 0,23 мг/кг почвы, в Буда-Кошелёвском - на 0,37 мг/кг почвы, в Кормянском - на 0,33 мг/кг почвы и в Чечерском районе - на $0,28 \mathrm{мг} /$ кг почвы.

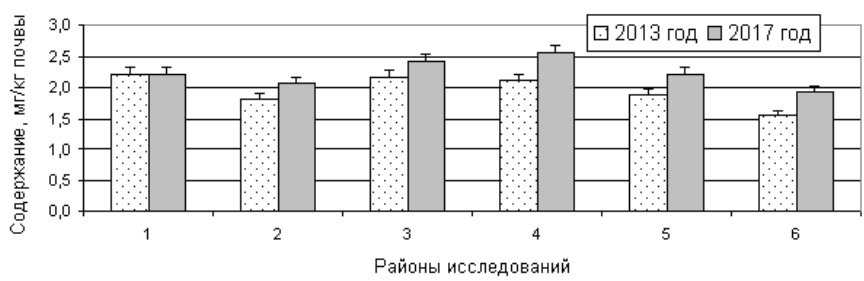

Рис. 2. Средневзвешенное содержание меди в луговой почве обследованных районов в 2013 и 2017 годах

Районы исследований:

1 - Октябрьский р-н, 2 - Мозырский р-н, 3 - Лоевский р-н,

4 - Буда-Кошелевский $\mathrm{p}-\mathrm{H}, 5$ - Кормянский, 6 - Чечерский

Колебания средневзвешенного показателя по отдельным районам в 2013 году находилось в пределах 1,55-2,20 мг/кг, в 2017 году - 1,832,20 мг/кг почвы. Средневзвешенное содержание в луговой почве меди в 2013 году было в количестве 1,96 мг/кг почвы, в 2017 году $-2,21$ мг/кг почвы или было больше на 0,25 мг/кг почвы.

Сравнение изменения средневзвешенных показателй содержания меди в пахотной и луговой почвах свидетельствует, что если за четырёхлетний период на пахотной почве прирост показателя составил 0,08 мг/кг почвы, то на луговых угодьях - 0,25 мг/кг. Следовательно, скорость накоплени меди в луговой почве оказалась более чем в 3,1 раза высокой в сравнении с пахотной почвой.

$\boldsymbol{B} \boldsymbol{b} \boldsymbol{о} \boldsymbol{д ы . ~ М е д ь ~ я в л я е т с я ~ н е з а м е н и м ы м ~ э л е м е н т о м ~ в ~ ж и з н и ~ р а с т е н и и ̆ ~}$ и животных. Почва относится к части биосферы, которая не только геохимически аккумулирует медь, но является естественным буфером, 
контролирующим её перенос в растения.

Анализ результатов исследований на содержание меди в почве сельскохозяйственных районов Гомельской области свидетельствует о колебании средневзвешенных показателей, в 2013 году, для пахотной почвы в пределах 1,44-2,16 мг/кг, в 2017 году - 1,42-2,17 мг/кг почвы, в луговой - соответственно $1,55-2,20$ и 1,83-2,20 мг/кг почвы. Наблюдается увеличение количества площадей с более высоким содержанием в почве меди. Если в 2013 году 47,9\% обследованных площадей пахотных почв имели удельную концентрацию меди более 1,51 мг/кг почвы, то по состоянию на 2017 год уже 50,2\%, соответственно луговых почв - с $54,2 \%$ до $60,9 \%$.

Средневзвешенное содержание меди в луговой почве в 2013 году имело значение на уровне 1,96 мг/кг почвы, через четыре года $2,21 \mathrm{мг} /$ кг, в пахотной почве соответственно - 1,72 и 1,80 мг/кг почвы. Следовательно, если за четырёхлетний период на пахотной почве прирост показателя составил 0,08 мг/кг почвы, то на луговых угодьях 0,25 мг/кг или более чем в 3,1 раза.

\section{References}

[1] Adriano, D. C. (2001). Trace Elements in the Terrestrial Environments. Biogeochemistry. Bioavailability and Risks of Metals. Springer-Verlag, New York.

[2] Alekseev, Yu. V. (1987). Tyazhelyie metallyi v pochvah i rasteniyah [Heavy metals in soils and plants]. Agropromizdat, Leningrad (in Russian).

[3] Chertko, N.K., \& Chertko, E.N. (2008). Geohimiya i ekologiya himicheskih elementov: spravochnoe posobie [Geochemistry and ecology of chemical elements: a reference]. Publishing Center of the Belarusian State University, Minsk (in Russian).

[4] Dobrovolskiy, V. V. (1983). Geografiya mikroelementov: globalnoe rasseyanie [The geography of trace elements: global scattering]. Myisl, Moscow (in Russian).

[5] Georgievskiy, V.I., Annenkov, B. N., \& Samohin, V.T. (1979). Mineralnoe pitanie zhivotnyih [Mineral food of animals]. Kolos, Moscow (in Russian).

[6] Izerskaya, L. A., \& Pashneva, G. E. (1977). Marganets, med i kobalt $\mathrm{v}$ pochvah Tomskoy oblasti [Manganese, copper and cobalt in the 
soils at Tomsk region]. Agrohimiya [Agricultural Chemistry], 5, 94 (in Russian).

[7] Kabata-Pendias, A., \& Pendias, H. (1989). Mikroelementyi v pochvah i rasteniyah [Trace elements in soils and plants]. Mir, Moscow (in Russian).

[8] Karpenko, A.F. (2012). Ekologo-ekonomicheskie problemyi agroproizvodstva Gomelskoy oblasti posle Chernobyilskoy katastrofyi [Ecological and economic problems of agricultural production at Gomel region after the Chernobyl disaster]. Delta, Bryansk (in Russian).

[9] Karpenko, A.F. (2018). Radioekologicheskoe sostoyanie selskohozyaystvennyih zemel Gomelschinyi [Radioecological condition of agricultural land of the Gomel region]. Biodiagnostika sostoyaniya prirodnyih i prirodno-tehnogennyih sistem [Biodiagnostics of the state of natural and natural-man-made systems]. Proceedings of XVI All-Russian scientific-practical conference with international participation (Kirov, December 3-5, 2018). Vyatka State University, Kirov, Book 1, 292-297 (in Russian).

[10] Podolyak, A. G., Karpenko, A.F., Lasko, T. V., \& Tagay, S. A. (2012). Rekomendatsii po optimizatsii sistemyi primeneniya udobreniy pod mnogoletnie zlakovyie i bobovo-zlakovyie travosmesi na zagryaznennoy radionuklidami torfyanyih pochvah [Recommendations of the system fertilizer application optimizing for perennial cereal and legume-cereal grass mixtures at radionuclide-contaminated peat soils]. Institute of Radiology, Minsk (in Russian).

[11] Podolyak, A. G., Valetov, V. V., \& Karpenko, A.F. (2017). Nauchnyie aspektyi selskohozyaystvennogo proizvodstva $\mathrm{v}$ postchernobyilskih usloviyah [Scientific aspects of agricultural production in postChernobyl conditions]. Ivana Shamyakin Mozyr State Pedagogical University, Mozyir (in Russian).

[12] Protasova, N. A., \& Scherbakov, A. P. (2003). Mikroelementyi (Cr, V, $\mathrm{Ni}, \mathrm{Mn}, \mathrm{Zn}, \mathrm{Cu}, \mathrm{Co}, \mathrm{Ti}, \mathrm{Zr}, \mathrm{Ga}, \mathrm{Be}, \mathrm{Ba}, \mathrm{Sr}, \mathrm{B}, \mathrm{I}, \mathrm{Mo})$ v chernozemah i seryih lesnyih pochvah Tsentralnogo Chernozemya [Trace elements (Cr, V, Ni, Mn, Zn, Cu, Co, Ti, Zr, Ga, Be, Ba, Sr, B, I, Mo) in Chernozems soils and gray forest soils of the Central Chernozems Region]. Voronezh State University Press Voronezh (in Russian).

[13] Savosko, V.N. (2009). Lokalnoe fonovoe soderzhanie tyazhelyih metallov v pochvah Krivorozhskogo zhelezorudnogo regiona [The heavy 
metals'local background content in soils at Kryvyi Rih iron-ore region]. Gruntoznavstvo [Soil Science Journal], 10, 3-4(15), 64-73 (in Russian).

[14] Savosko, V.N. (2010). Assotsiatsii tyazhelyih metallov v pochvah Krivorozhskogo zhelezorudnogo regiona [The heavy metals' associations in soils at Kryvyi Rih ore mining region]. Gruntoznavstvo [Soil Science Journal], 11, 1-2(16), 85-90 (in Russian).

[15] Savosko, V. M. (2016). Tyazhelyie metallyi v pochvah Krivbassa [Heavy Metals in Soils at Kryvbas]. Kryvyi Rih, Dionat (in Russian).

[16] Shkolnik, M.M. (1974). Mikroelementyi v zhizni rasteniy [Trace elements in plant life]. Nauka, Moscow (in Russian).

[17] Sparks, D. L. (2003). Environmental soil chemistry. Elsevier Science, San Diego.

[18] Sposito, G. (2008). The Chemistry of Soils. Oxford University Press, New York.

[19] Tan, K. H. (1982). Principles of soil chemistry. Marcel Dekker Inc, New York.

[20] Yakushevskaya, I. V., \& Martyinenko, A. G. (1972). Mikroelementyi v landshaftah kolochnoy lesostepi [Trace elements in landscapes of the colossal forest-steppe]. Pochvovedenie [Soviet Soil Science], 4, 92 (in Russian).

[21] Zborischuk, Yu.N., \& Zyirin, N. G. (1978). Med i tsink v pahotnom sloe pochv Evropeyskoy chasti SSSR [Copper and zinc in the soils arable layer at the European part of the USSR]. Pochvovedenie [Soviet Soil Science], 1, 38 (in Russian). 


\title{
COPPER IN ARABLE AND MEADOW SOILS OF GOMEL REGION
}

\author{
A. G. Podolyak ${ }^{1}$, A. F. Karpenko ${ }^{2}$ \\ 1 - Gomel Region Planning and Surveying Station of Agricultural \\ Chemicalization, Gomel, Belarus \\ ${ }^{2}$ - Francisk Scorina Gomel State University, Gomel, Belarus
}

\begin{abstract}
The results of studying copper concentrations in arable and meadow soils in different areas of Gomel region are analyzed in the article. This research was carried out with an interval of four years. The fluctuations of weighted average values of copper in arable and meadow soils were in the range of $1.44-2.16$ and $1.55-2.20 \mathrm{mg} / \mathrm{kg}$ in 2013 , and, respectively, $1.42-2.17$ and $1.83-$ $2.20 \mathrm{mg} / \mathrm{kg}$ in 2017 . The areas with increased concentrations of copper in soils are expanding over time. In 2013, specific concentrations of copper above $1.51 \mathrm{mg} / \mathrm{kg}$ were found in $47.9 \%$ of examined arable soils and $54.2 \%$ of grassland soils. In 2017 , the areas increased to 50.2 and $60.9 \%$, respectively.
\end{abstract}

Keywords: soils, copper, concentration, sufficiency.

Citation:

Podolyak, A. G., \& Karpenko, A.F. (2019). Med v pahotnoy i lugovoy pochve Gomelschinyi [Copper in arable and meadow soils

APA of Gomel region]. Ekolohichnyi visnyk Kryvorizhzhia [Ecological Bulletin of Kryvyi Rih District], 4, 56-66, DOI: 10.31812/eco-bulletinkrd.v4i0.2560 (in Ukrainian).

Подоляк А.Г., Карпенко А.Ф. Медь в пахотной и луговой почве 8302:2015 Гомельщины. Екологічний Вісник Криворіжжя. 2019. Вип. 4. C. 56-66. DOI: 10.31812 /eco-bulletin-krd.v4i0.2560. 